\title{
A FINANCIAL INCLUSION INDEX FOR INDONESIA
}

\author{
Hilman Hanivan* and Nasrudin Nasrudin** \\ * Statistics Indonesia, Indonesia. Email: hilmanhaniv@gmail.com \\ ** Statistics Indonesia, Indonesia. Email: nasrudin@stis.ac.id
}

\begin{abstract}
Numerous studies have constructed financial inclusion indexes for Indonesia, using a multidimensional approach. However, there is a problem with the methodology, which assumes that all the dimensions play the same role in defining financial inclusion, since they are based on equal weighting criteria. This paper aims to obviate concerns with the methodology by developing a more empirically based index, namely, a weighted multidimensional index of financial inclusion based on two-stage principal component analysis. In other words, we endogenize the weights. We find that usage is the most important dimension in defining financial inclusion in Indonesia, followed by availability and access.
\end{abstract}

Keywords: Financial inclusion; Principal component analysis; Unequal weights.

JEL Classifications: C18; C43; G20; G21.

Article history:

Received : April 24, 2019

Revised : June 14, 2019

Accepted : September 09, 2019

Available online : October 15, 2019

https://doi.org/10.21098/bemp. v22i3.1056 


\section{INTRODUCTION}

Financial inclusion ${ }^{1}$ is perceived as a cornerstone of economic development. Primarily, financial inclusion is considered to be an important ingredient in assisting countries meet some of their sustainable development goals, particularly with respect to eliminating poverty and promoting shared economic growth (Burgess and Pande, 2005; Beck et al. 2007; Beck et al. 2009). According to Greenwood and Jovanovic (1990), excluding poor people from the financial system is unlikely to facilitate shared economic growth, since such exclusion will likely deepen income inequality.

According to the World Bank's Global Findex database, Indonesia is a developing country where, as of $2017,48 \%$ of the adult population has an account in a financial institution. This number is lower than in other developing countries, such as Malaysia (85\%), Thailand (82\%), India (80\%), Kenya (82\%), Sri Lanka (74\%), and South Africa (69\%). An important feature of this database is that it identifies eight reasons why Indonesians do not have a financial account. Figure 1 summarizes the situation: around $72 \%$ of adults with no account cited insufficient funds as the reason for not having an account. The location of the financial institution was a reason for around 33\% of adults. Only a small percentage of adults voluntarily excluded themselves from the financial system, due to either religious beliefs (5.24\%) or lack of motivation to have an account $(1.69 \%)$.

\section{Figure 1. Reasons that Prevented Indonesia's Unbanked Adult Population to Have a Financial Account in 2017}

This figure provides a list of reasons why the unbanked adult Indonesian did not have a financial institution account based on Global Findex Database by the World Bank. The percentages show the the fraction of the unbanked who agreed on each reason.

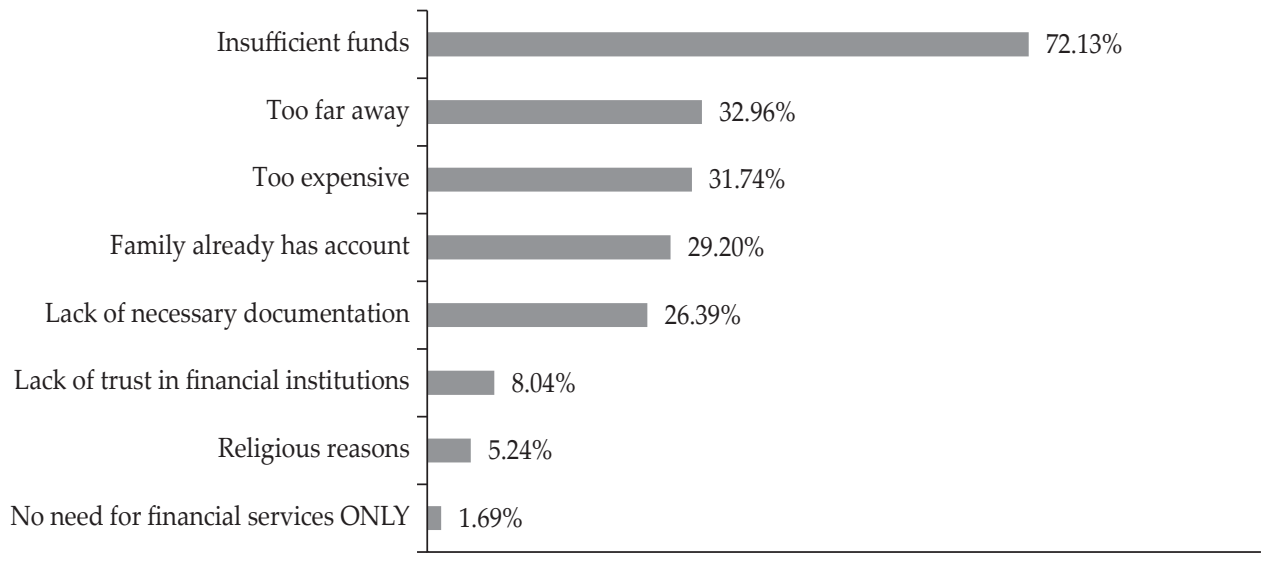

\footnotetext{
1 According to Sarma and Pais (2011), financial inclusion refers to a process that ensures ease of access, availability, and usage of the formal financial system by all members of an economy. Allen et al. (2016) define financial inclusion as the use of formal financial services.
} 
From these discussions, what is clear is that, when it comes to financial inclusion, Indonesia lags behind some emerging and developing countries. The question we then ask is, how accurately can we measure financial inclusiveness? An important issue characterizing previous literature on Indonesia's financial inclusion is the allocation of equal weights to every dimension of the financial inclusion.

Ummah and Nuryatono (2013), for instance, construct an index of financial inclusion using the panel data of several Asia countries, including Indonesia. Assuming that each dimension comprises the exact same portion of a role in determining financial inclusion, they use equal weighting in their empirical analysis. Ummah et al. (2015) also assign equal weightings to construct a financial inclusion index using the panel data of 33 provinces in Indonesia. In their data set, the lower limit of each dimension is predefined as zero, while the upper limit of each dimension is defined as the maximum value of the empirical data. Moreover, Sanjaya and Nursechafia (2016) construct an index of financial inclusion using the panel data of 33 provinces in Indonesia from 2008 to 2014. Their research also applies equal weightings. Additionally, Umar (2017) assigns equal weights to construct an index of Sharia financial inclusion in Indonesia. Although the studies alluded to above differ in their use of each of the dimensions, none consider endogenously determining the dimensions' weights. Our main concern is still that studies on Indonesia assume that each dimension carries the same weight. This assumption of homogeneity can be misleading and can therefore bias our understanding of the index. This point is well made by Cámara and Tuesta (2014), who argue that arbitrary weighting in the process of constructing composite indexes to measure financial inclusion is a questionable and that the exogenous choice of weights lacks scientific rigor.

According to the Organisation for Economic Co-operation and Development (OECD), (2008), weights are essentially a set of value judgments. Equal weighting is one of the most common approaches due primarily to its simplicity. On the other hand, equal weighting implies that all variables play an equal role in the composite indicator, and it also often disguises the absence of a statistical or an empirical basis, for example, when there is insufficient knowledge related to the field or a lack of consensus on the alternative.

Our paper contributes to the construction of a weighted multidimensional financial inclusion index for Indonesia. Using two-stage Principal Component (PC) Analysis (PCA), we find this index improves on existing financial inclusion indexes of Indonesia in a way that is able to eliminate subjectivities or the imposition of a weight assignment. This is because the weight of each indicator/ dimension is obtained from a statistical estimation of the empirical data, which, in turn, can also show whether each dimension is equally weighted, as most recent Indonesian studies assume, or whether the weight of a particular dimension dominates. Moreover, this approach enables us to perform a deeper analysis at the sub-index level (dimension level), since we also estimate the weights of each indicator in every dimension. 


\section{METHODOLOGY AND DATA}

Composite indicators can illustrate complex issues in many fields. They have been a useful tool to show the progress of a country's development in a specific period (Saltelli, 2007). The methodology used to construct the index of financial inclusion in this paper follows that of the OECD (2008). According to the OECD (2008), building a composite indicator involves several steps. First, we need to develop a theoretical framework, where we define what is being measured by the composite indicator. The next step is the variable selection. Variables should be selected on the basis of their relevance to the phenomenon being measured. Nevertheless, proxy measures are sufficient in the absence of the desired data. Following this, we also need to consider data standardization, since differences in the units of measurement between variables do arise and thus need to be controlled for. There are certain approaches to standardize the data, and we adopt a normal distribution transformation. The last step is weighting, which is endogenously estimated through a two-stage PCA (see the subsection on index construction for details). Lastly, after obtaining the index, we link that index to theoretically related macroeconomic variables to test the validity or explanatory power of our index in capturing information on the degree of financial inclusiveness in Indonesia.

\section{A. Index Construction}

In this paper, we adapt the financial inclusion's dimension defined by Sarma and Pais (2011), because it represents a comprehensive measure of financial inclusiveness. The components of financial inclusion are discussed next. Table 1 provides a list of the input indicators.

\section{Table 1.}

\section{Details of Variables}

This table presents a list of variable names (column 1) used in constructing each dimension, including their respective definitions (column 2). All variables are obtained from Statistik Sistem Keuangan Indonesia - Bank Indonesia. Column 1 is the name of the indicator. Columns 3, 4, 5 and 6 contain selected descriptive statistics for each variable, namely minimum (min.) value maximum (max.) value, variable average, and its standard deviation (SD).

\begin{tabular}{|c|c|c|c|c|c|}
\hline Variable & Definition & Min. & Max. & Average & SD \\
\hline Account & $\begin{array}{l}\text { Number of third-party-funding accounts } \\
\text { per } 1,000 \text { adult }\end{array}$ & 624.40 & 1588.99 & 994.99 & 253.43 \\
\hline Debit Card & Number of debit cards per 1,000 adult & 360.68 & 926.02 & 618.26 & 159.32 \\
\hline Credit Card & Number of credit cards per 1,000 adult & 81.25 & 92.30 & 87.18 & 3.27 \\
\hline E-Money Card & Number e-money cards per 1,000 adult & 82.40 & 859.54 & 270.24 & 185.27 \\
\hline Branches & Number of ATMs per 100,000 adult & 12.33 & 15.93 & 14.93 & 0.94 \\
\hline ATMS & $\begin{array}{l}\text { Number of commercial bank branches } \\
\text { per 100,000 adult }\end{array}$ & 25.10 & 55.67 & 46.39 & 9.33 \\
\hline $\begin{array}{l}\text { Debit } \\
\text { Transactions }\end{array}$ & Number of transactions per debit card & 2.74 & 3.87 & 3.34 & 0.21 \\
\hline $\begin{array}{l}\text { Credit } \\
\text { Transactions }\end{array}$ & Number of transactions per credit card & 1.11 & 1.77 & 1.44 & 0.15 \\
\hline Credit-to-GDP & $\begin{array}{c}\text { Domestic Credit to the private sector as \% } \\
\text { of nominal quarterly GDP }\end{array}$ & 0.89 & 1.18 & 1.08 & 0.07 \\
\hline
\end{tabular}


- Access. This dimension measures the penetration of financial services in society. It implies that financial inclusion is a condition under which formal financial services have as many users as possible. We use four indicators to measure the penetration of formal financial services. First, we use the number of third-party fund bank accounts per 1,000 adults in the population instead of the fraction of the adult population with a bank account, due to unavailability of time series data. In addition, we utilize the number of debit cards per 1,000 adults, the number of credit cards per 1,000 adults, and the number of electronic money accounts per 1,000 adults in the population.

- Availability. This dimension describes how easily banking services are utilized by their users. It is related to banking infrastructure readiness, that is, reachability by all. For this dimension, we include the numbers of commercial bank branches and of ATMs per 100,000 adults as indicators.

- Usage. This dimension is used to anticipate the possibility of an observation with a high portion of people who have an account but make very low utilization of banking products. We use three indicators to build this dimension. We use domestic credit to the private sector as the percentage of the nominal quarterly gross domestic product (GDP), where the credit-to-GDP ratio has been widely used in measuring the usage dimension (Beck et al., 2007; Park \& Mercado, 2018; Sharma, 2016). Moreover, we include the number of transactions per debit card and per credit card to assess whether the utilization of these cards has been increasing.

Using these three dimensions, we construct an index of financial inclusion, IFI, for Indonesia. The IFI index should be able to show the progress of the embodiment of financial inclusion in an economy over time. We gather the monthly data for each indicator from January 2012 to December 2018, because of data constraints, such that we obtain observations for 84 months. All the data are from Bank Indonesia.

We adopt a two-stage PCA approach, following Cámara and Tuesta (2014). This methodology is also used in other financial inclusion studies, such as that of Park and Mercado (2018). In brief, our PCA has two estimation stages in the index building process. In the first stage, we estimate the scores of three dimensions (sub-indexes)—access, availability, and usage-and the weights of the respective indicator. In the second stage, we estimate the overall financial inclusion index and the dimension weights.

In the first stage, we estimate the score of each dimension, that is, the three unobserved variables $D_{i}^{A c}, D_{i}^{A v}$, and $D_{i}^{U}$, where the superscripts denote access, availability, and usage, respectively. We first find the scores of all the principal components of each of the three dimensions, since the principal components of each dimension are the linear combination of their respective input indicators, as follows:

$$
P C_{k}=\sum \delta_{k p} X_{p}
$$

Note that the number of PCs for each dimension is as many as the number of indicators used in that dimension. In the above equation, $\delta_{k p}$ is the component loading, or correlation coefficient, between the $k$ th PC and the $p$ indicator. 
Therefore, the access dimension, which is constructed with four indicators, has four PCs, which will be obtained for each observation from the following equations:

$$
\begin{aligned}
P_{1 t}= & \delta_{11} \text { Account }_{t}+\delta_{12} \text { Debit Card }_{t}+\delta_{13} \text { Credit Card }_{t}+\delta_{14} \text { Emoney Card }_{t} \\
& \cdot \\
& \cdot \\
P_{4 t}= & \delta_{41} \text { Account }_{t}+\delta_{42} \text { Debit Card }_{t}+\delta_{43} \text { Credit Card }_{t}+\delta_{44} \text { Emoney Card }_{t}
\end{aligned}
$$

The PC scores for the availability and usage dimensions are similarly computed. After we calculate each PC score of every dimension, we obtain the score of each dimension as the weighted average of the respective PC, as follows:

$$
\begin{aligned}
& D_{t}^{A c}=\frac{\sum_{j, k=1}^{4} \lambda_{j}^{A c} P C_{k t}^{A c}}{\sum_{j, k=1}^{4} \lambda_{j}^{A c}} \\
& D_{t}^{A v}=\frac{\sum_{j, k=1}^{2} \lambda_{j}^{A v} P C_{k t}^{A v}}{\sum_{j, k=1}^{2} \lambda_{j}^{A v}} \\
& D_{t}^{U}=\frac{\sum_{j, k=1}^{3} \lambda_{j}^{U} P C_{k t}^{U}}{\sum_{j, k=1}^{3} \lambda_{j}^{U}}
\end{aligned}
$$

where

$D_{t}^{A c} \quad$ : score of the access dimension for the $t$ th observation

$D_{t}^{A v} \quad$ : score of the availability dimension for the th observation

$D_{t}^{u} \quad$ : score of the usage dimension for the $t$ th observation

$\lambda_{j}^{A c} \quad$ : eigenvalue for the $j$ th PC of the access dimension

$\lambda_{j}^{A v} \quad$ : eigenvalue for the $j$ th PC of the availability dimension

$\lambda_{j}^{u} \quad$ : eigenvalue for the $j$ th PC of the usage dimension

$P C_{k t}^{A c}: k$ th PC score of the access dimension for the $t$ th observation

$P C_{k t}^{A v} \quad: k$ th PC score of the availability dimension for the $t$ th observation

$P C_{k t}^{u} \quad: k$ th PC score of the usage dimension for the th observation

It is known that, for $j=k, \lambda_{1}>\lambda_{2}>\cdots>\lambda_{j}$, where $\lambda_{j}$ represents the variance of the $k$ th PC, accounting for total variability in each dimension, such that the first PC must account for the largest proportion of the variation in each dimension.

Normally, in PCA, we should decide how many PCs to hold for each dimension with regard to the substantial proportion of the total variation (usually $75 \%$ minimum) and remove the remainder. Nevertheless, since our goal is to compute an index of financial inclusion that can capture all the information from all the indicators, instead of data reduction, we use the equations above so that our index can account for all the information from the input indicators. 
After we obtain the score of each dimension, we continue to the secondstage PCA, where we replicate the procedure from the first stage, changing some details, that is, using the estimated score of the three dimensions (sub-indexes of IFI) analogous to the input indicators in the first stage. We estimate the index of financial inclusion with the following equations:

$$
\begin{aligned}
& P C_{1 t}=\varphi_{11} D_{t}^{A c}+\varphi_{12} D_{t}^{A v}+\varphi_{13} D_{t}^{U} \\
& P C_{2 t}=\varphi_{21} D_{t}^{A c}+\varphi_{22} D_{t}^{A v}+\varphi_{23} D_{t}^{U} \\
& P C_{3 t}=\varphi_{31} D_{t}^{A c}+\varphi_{32} D_{t}^{A v}+\varphi_{33} D_{t}^{U} \\
& I F I_{t}=\frac{\sum_{j, k=1}^{3} \lambda_{j} P C_{k t}}{\sum_{j, k=1}^{3} \lambda_{j}}
\end{aligned}
$$

where

IFI $\quad$ : index of financial inclusion for the $t$ th observation

$\lambda_{j} \quad$ : eigenvalue for the $j$ th PC

$P C_{k t} \quad: k$ th PC score for the $t$ th observation

$\varphi_{11^{\prime}}, \varphi_{12^{\prime}} \varphi_{13}:$ loadings of the respective dimension (sub-indexes)

After we obtain the IFI score, we transform it into a normal standardized form so that IFI will range from zero to one. Therefore, the value of one is obtained for any observation (month) with the highest IFI score, which also implies the most ideal financial inclusion embodiment in Indonesia from 2012 to 2018 with that observation, and vice versa.

Finally, we obtain the weights of each dimension, $w_{k^{\prime}}$ in the index of financial inclusion with the following equation:

$$
w_{k}=\frac{\sum_{j=1}^{3} \lambda_{j} \varphi_{j k}}{\sum_{j=1}^{3} \lambda_{j}}, k=1,2,3
$$

The weights for each indicator at the dimension level are also calculated using a similar formula as above. The weights assigned to each dimension reflect its empirical importance in defining financial inclusion in Indonesia. The larger the weight, the more important the dimension.

\section{RESULTS}

\section{A. Estimation Results}

This section presents the results. The computed weights for the indicators of each dimension are presented in Table 2. The cumulative variance for an extra PC is also provided for each dimension in Table 3. 
Table 2.

First Stage Principal Components Estimates

This table presents the estimation result of the first piricipal compnent (PC) Analysis in constructing all dimensions. Column 1 contains the name of the variable used to measure the related dimension. Columns 2, 3, 4, and 5 have the loading vector of each PC. Column 6 is the normalized weight accounted for each indicator in defining the related dimension. The eigenvalues of each PC are provided in the last row of each panel.

\begin{tabular}{lccccc}
\hline Variable & PC1 & PC2 & PC3 & PC4 & Weight \\
\hline \multicolumn{7}{c}{ Panel A: Access } & & & \\
\hline Account & 0.5327 & -0.3113 & -0.2913 & 0.7311 & 0.2297 \\
Debit Card & 0.5454 & 0.0679 & -0.5812 & -0.6001 & 0.2651 \\
Credit Card & 0.3963 & 0.8545 & 0.2794 & 0.1863 & 0.2869 \\
E-Money Card & 0.5115 & -0.4103 & 0.7066 & -0.2659 & 0.2184 \\
\hline Eigen Values & 3.2172 & 0.6667 & 0.0882 & 0.0279 & \\
\hline \multicolumn{7}{c}{ Panel B: Availability } & & & \\
\hline Branches & 0.7071 & -0.7071 & - & - & 0.4909 \\
ATMS & 0.7071 & 0.7071 & - & - & 0.5091 \\
\hline Eigen Value & 1.9642 & 0.0358 & - & - & \\
\hline \multicolumn{7}{c}{ Panel C: Usage } & & & \\
\hline Debit Transactions & -0.1618 & 0.9860 & 0.0392 & - & 0.2046 \\
Credit Transactions & 0.7000 & 0.0867 & 0.7089 & - & 0.4441 \\
Credit-to-GDP & 0.6956 & 0.1421 & -0.7042 & - & 0.3513 \\
\hline Eigen Value & 1.7645 & 0.9806 & 0.2549 & - & \\
\hline
\end{tabular}

Table 3.

\section{Cumulative Variance Explained by Components at First Stage PCA}

This table has information about the cumulative variance explained by components at the first stage PCA. Column 1 contains the principal component (PC). Column 2 contains the portion of total variance contained by each PC. Column 3 records cumulative variance for each addition of PC.

\begin{tabular}{lcc}
\hline Component & Variance Explained & Cumulative Variance \\
\hline \multicolumn{3}{c}{ Panel A: Access } \\
\hline PC1 & $80.43 \%$ & $80.43 \%$ \\
PC2 & $16.67 \%$ & $97.10 \%$ \\
PC3 & $2.20 \%$ & $99.30 \%$ \\
PC4 & $0.70 \%$ & $100.00 \%$ \\
\hline \multicolumn{3}{c}{ Panel B: Availability } \\
\hline PC1 & $98.21 \%$ \\
PC2 & $1.79 \%$ \\
\hline PC1 & Panel C: Usage \\
PC2 & $58.82 \%$ \\
PC3 & $32.69 \%$ & $100.00 \%$ \\
\hline
\end{tabular}

We see that, for the access dimension, the largest weight is given to credit card. Therefore, credit card is the most important indicator in driving the access dimension. Nevertheless, the weights tend to be evenly distributed, with no indicator dominating the weighting. In addition, the first PC explains $80.43 \%$ of 
the total variance. The first component is also noted to have contributions from all the indicators. However, credit card allocates part of its information to the second PC by contributing its high loading to that component. This could indicate that owning a credit card also represents a wider field of financial inclusion, since most people tend to have a more basic financial product (e.g., a debit card or a savings account) before a credit card, so that credit card could be considered more accurate in measuring the access dimension in a more consolidated way.

This case should remind us that, had we proceeded with regular PCA earlier, the first component, which accounted for $80.43 \%$ of the total variation, would have led us to pick the first component only to explain the access dimension. In other words, we would have ignored the remainder of the PCs, which would have been a disadvantage in the index building, since they are still important.

For the availability dimension, we find that both indicators have relatively the same weight, although the weight of ATMs is slightly larger than that of branches. This result appears reasonable, since ATMs are able to provide basic yet highly in-demand banking services at locations where bank's branch office might find it costly to operate. Regarding the fact that the first PC already contains $98.21 \%$ of the total variation, it is safe to say that both branches and ATMs truly measure the same latent structure of financial inclusion.

For the usage dimension, we find that credit transactions has the largest weight, followed by credit-to-GDP and debit transactions. Therefore, it is important to account for credit transactions in defining the usage dimension of financial inclusion. According to Table 3, the first PC contributes only $58.82 \%$ to the total variance. Moreover, it is important to note that credit transactions and credit-to-GDP tend to have similar positive loadings in the first component, while debit transactions has a very small negative loading. Instead, the loading of debit transactions is highest and dominates in the second component, where the other two components are found to have small loadings. This result indicates that debit transactions might measure a different latent structure from that measured by the other two indicators.

In the second stage, we calculate the weights for each dimension of IFI as presented in Table 4 . The cumulative variance added by an extra component is presented in Table 5. The second-stage estimation shows that usage has the largest weight in defining IFI (0.3680), followed by availability (0.3179) and access (0.3141). This finding implies that usage is the most important dimension or sub-index in defining the financial inclusion index for Indonesia. This estimation result also implies that there should have been a weight adjustment for each dimension in constructing the index in order to capture the empirically based information. Consequently, if equal weighting is used in the process of indexing, it might not be able to capture the empirically based information accounted for in each dimension. Moreover, note that the first component already contains $89.07 \%$ of the total variation and the three dimensions provide relatively even contributions. This indicates that these three indicators measure the same latent structure. Nevertheless, usage also allocates part of its information to the second PC, such that usage contributes to the overall IFI through both the first and second PCs, which is how usage gains its importance in defining financial inclusion. 
Table 4.

\section{Second Stage Principal Components Estimates}

This table presents the estimation result of the first Principal Component (PC) analysis in constructing the Index of Financial Inclusion (IFI). Column 1 is the name of the dimension used to measure the grand latent variable IFI. Columns 2, 3, and 4 are the loading vector of each PC. Column 5 contains the normalized weight accounted for each dimension in defining IFI. The eigenvalues of each PC are provided in the last row.

\begin{tabular}{lcccc}
\hline \multirow{2}{*}{ Dimension } & \multicolumn{4}{c}{ Index of Financial Inclusion } \\
\cline { 2 - 5 } & PC1 & PC2 & PC3 & Weight \\
\hline Access & 0.5826 & -0.508 & 0.6345 & 0.3141 \\
Availability & 0.5954 & -0.2647 & -0.7586 & 0.3179 \\
Usage & 0.5533 & 0.8197 & 0.1483 & 0.3680 \\
\hline Eigen value & 2.672 & 0.2689 & 0.0591 & \\
\hline
\end{tabular}

Table 5.

Cumulative Variance Explained by Components at Second Stage PCA

This table has information about the cumulative variance explained by components at second stage Principal Component (PC) Analysis for the Index of Financial Inclusion (IFI). Column 1 contains the PC. Column 2 contains the portion of total variance contributed to by each PC. Column 3 contains cumulative variance for an additional PC.

\begin{tabular}{lcc}
\hline \multicolumn{3}{c}{ Index of Financial Inclusion } \\
\hline Components & Contained Variance & Cumulative Variance \\
\hline PC1 & $89.07 \%$ & $89.07 \%$ \\
PC2 & $8.96 \%$ & $98.03 \%$ \\
PC3 & $1.97 \%$ & $100.00 \%$ \\
\hline
\end{tabular}

\section{B. Some Details}

To enrich the analysis of the scores of IFI and its dimensions, Figure 2 is provided. Note that IFI and the three dimensions are normalized for better data visualization. The line chart shows that IFI has a positive trend, which implies that the embodiment of financial inclusion in Indonesia has been increasing for the last seven years. However, during its overall positive progress, fluctuations were impossible to avoid.

\section{Figure 2. Financial Inclusion in Indonesia}

This figure provides a line chart of Indonesia's monthly Index of Financial Inclusion obtained from the second stage PCA from January 2012 to December 2018. The three dimensions of financial inclusion is also presented in the lower panel. Note that all of these measures are normalized to give better data visualization.

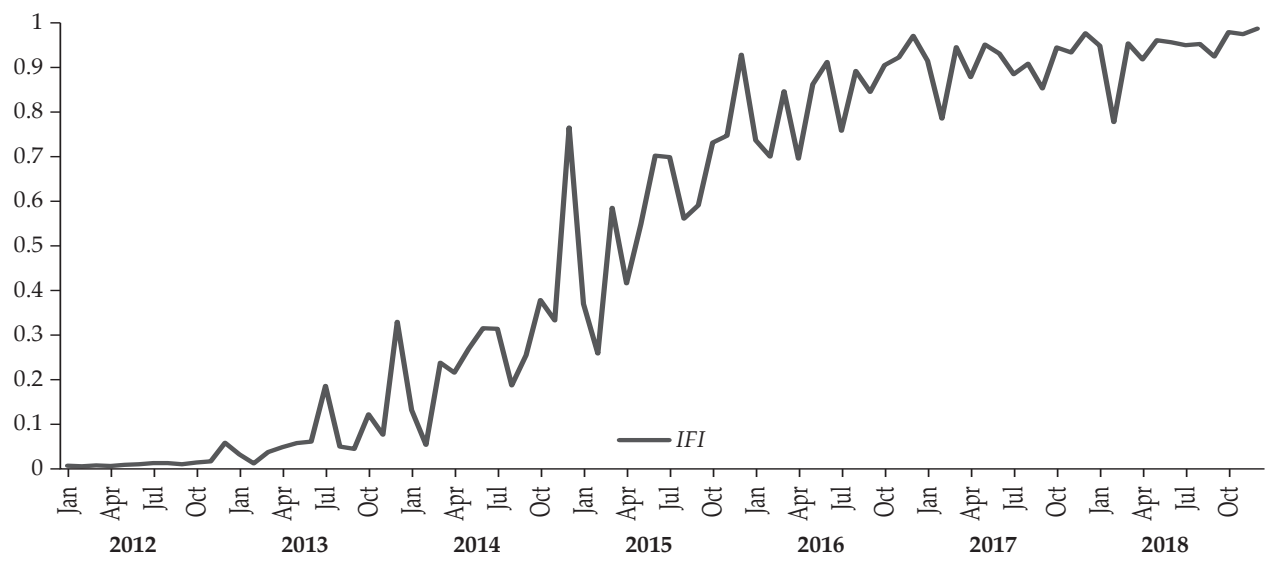




\section{Figure 2. Financial Inclusion in Indonesia (Continued)}

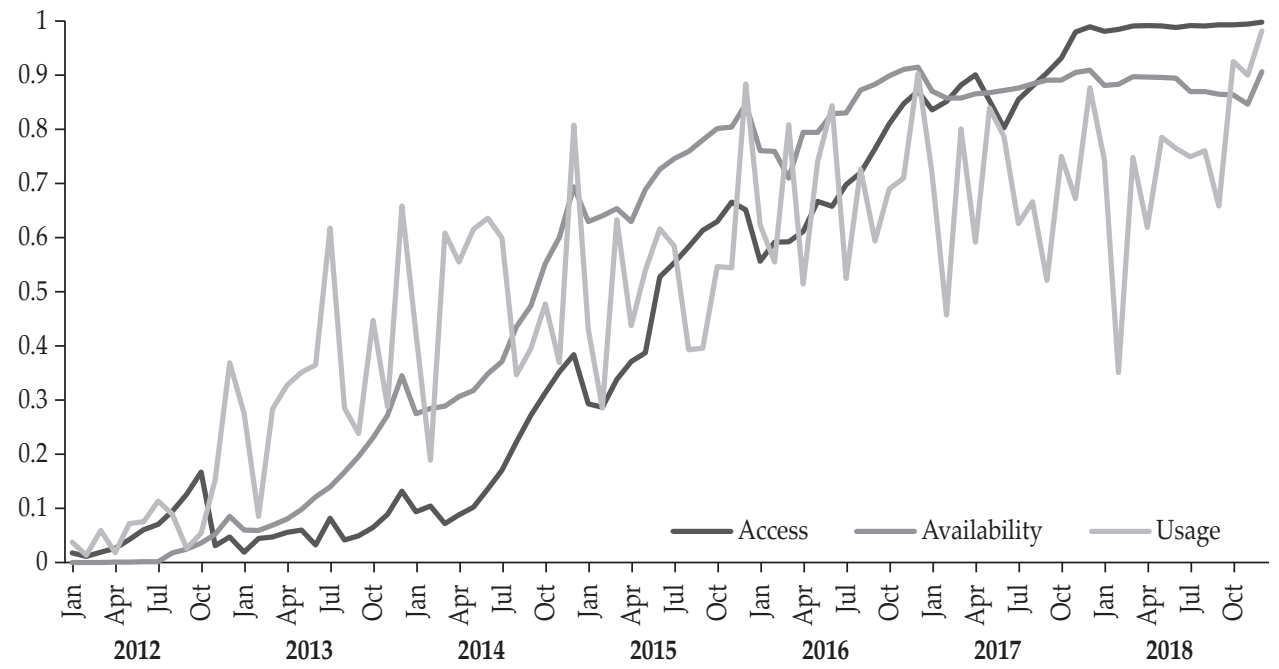

In November 2012, the access dimension faced its most significant decline over our sample of data, caused by a $4.7 \%$ decrease of credit card. This was due in part to Bank Indonesia's (2012:Q4) policy regarding credit card holder eligibility, which was made more stringent. Only adults over the age of 21 with a minimum monthly income of Rp 3 million could become a principal card holder, with implications for credit transactions. Overall, a slight increase (0.0025) in IFI was noted in the same month, mainly because the credit card-related policy change did not negatively impact availability or usage.

In August 2013, IFI declined by about 0.1361 points, which coincided with a 0.3325 -point decrease in usage, along with a 0.04 decrease in access and a 0.0273 increase in availability. In addition, decreasing usage also coincided with a $10.9 \%$ decline in debit transactions and a $8.89 \%$ decline in credit transactions. Over the same period, the policy rate set by Bank Indonesia was 7\%, the highest since 2009. A high interest rate implies a high value for money, which encourages people to spend less and save more, which seems to have contributed to the decreases in debit transactions and credit transactions.

The IFI, rose significantly in December 2013. This growth was supported by growth in all dimensions. The performance of the access dimension was due to the electronic money card (with a $25 \%$ growth in e-money card) as it entered the transportation sector, specifically the integrated ticketing system of commuter trains, which was initially aimed at improving the efficiency of its business process . The usage dimension was boosted due to seasonal effects: December is considered a high demand season when spending is also high.

Furthermore, in March 2014, IFI increased by about 0.1845 points, one of the largest increases on record. The positive progress also coincided with a 0.419-point increase in usage, which was also one of the biggest increases on record, even though access decreased by 0.0321 points at the same time, while availability was stable. 
By April 2016, even though availability was experiencing a 0.0845-point increase and access was showing a moderate increase, IFI fell by about 0.1510 points.

All the dimensions of financial inclusion in Indonesia have been undeniably growing over the last seven years, supported by policy. A feature of these patterns of IFI behavior is an indication of how the usage dimension has played a significant role in defining financial inclusion in Indonesia, with most of the structural changes that impacted IFI mostly coinciding with fluctuations in the usage dimension. In this regard, usage and IFI are positively correlated.

\section{Link to Macroeconomic Indicators}

In this section, we link IFI to several macroeconomic indicators by calculating their Pearson correlation coefficients to test the validation or explanatory power of our index. The list of macroeconomic indicators and their correlation coefficients are provided in Table 6. These macroeconomic indicators were obtained from Statistics Indonesia. The macroeconomic data are noted in column 1 of Table 6 and include the poverty rate, the Gini ratio, the real GDP per capita, and the human development index. These data are reported annually for the period 2012-2018, except for poverty and the Gini ratio, which are biannual.

Table 6.

\section{Linking Index of Financial Inclusion to Several Macroeconomic Indicators}

This table provides a snapshot of the link between the finanical inclusion measure and macroeconomic indicators using the Pearson correlation analysis. Macroeconomic variables are noted in Column 1 while the obtained pearson correlation coefficient is in Column 2. Noted that we use biannual data for Poverty Rate and Gini Ratio, starting from 2012 to 2018, and we use annual rate real GDP per capita and Human Development Index from 2012 to 2018. Finally,

\begin{tabular}{lc}
\hline Macroeconomic Indicator & Pearson Correlation Coefficient \\
\hline Poverty Rate & $-0.8956^{*}$ \\
Gini Ratio & $-0.8484^{*}$ \\
Real GDP per capita & $0.8696^{*}$ \\
Human Development Index & $0.8845^{*}$ \\
\hline
\end{tabular}

* significant at $\alpha=0.05$

On a semesterly basis, first, we find a strong negative correlation (-0.8956) between IFI and the poverty rate. A negative correlation of this sort has also been observed in the literature (e.g., Brune et al., 2011; Burgess \& Pande, 2005; Honohan, 2008; Jeanneney \& Kpodar, 2011; Park \& Mercado, 2015). This negative relation is attributed to financial inclusion providing greater access to financial services, allowing people to smooth their consumption and to engage in productive activities. We also find a strong negative correlation (-0.8484) between IFI and the Gini ratio, consistent with the evidence of Beck et al. (2007), Neaime and Gaysset (2018), Park and Mercado (2015), and Sarma and Pais (2011). This negative relation is attributed to a decline in income inequality with improving financial inclusion as more people in the lower income strata gain access to financial services.

On the other hand, a strong positive correlation is observed between IFI and the per capita GDP (0.8696) and between IFI and the human development index (0.8845). Allen et al. (2016), Kim et al. (2018), and Sarma and Pais (2011) show that 
financial inclusivity improves incomes, and Kuri and Laha (2011) and Sarma and Pais (2011) have documented a relation between human development and IFI.

The main message from this correlation-based analysis is that all four macroeconomic aggregates are correlated with IFI in a bivariate manner. The sign of the correlation is theoretically consistent with expectations; that is, poverty measures are negatively correlated, while income/development measures are positively correlated. From this, we conclude that IFI is a reasonably good measure of financial inclusiveness.

\section{CONCLUSION}

This study is concerned with Indonesia's financial inclusiveness. Several attempts have been made at constructing a financial inclusiveness index for Indonesia; however, we take issue with their approach. We question the equal weighting given to all dimensions of inclusiveness and propose estimating the specific weights empirically, based on data. We thus create an index of Indonesia's financial inclusiveness. Our analysis shows that, out of usage, access, and availability (the three dimensions popularly considered in this literature), it is usage that stands out, with a weight of around $37 \%$. We conclude by developing a connection between the index and other macroeconomic data. We show that the correlations between the index and poverty measures (the poverty rate and the Gini ratio) are negative, and those between the index and income/development measures are positive, all statistically different from zero. Overall, there is support suggesting that financial inclusiveness has an economic relation with the rest of the economy.

While we contribute to the literature on the importance of dimensions in financial inclusiveness and to the development of such an index for Indonesia, two limitations dictate an agenda for future research. What we discover for Indonesia might not hold for Indonesian provinces, which are economically and socially heterogeneous. Therefore, a study at the province level will deliver greater insights from a policy perspective. Second, recent studies, such as those of Narayan and Popp (2010, 2013) and Sharma et al. (2019), show the relevance of structural breaks to Indonesia and the global macroeconomic data. Structural breaks could also characterize the financial inclusion index we have developed. In this paper, we assume nothing about the role of breaks and leave this issue for future research. In both these future research directions, our study sets the foundation and, indeed, the motivation.

\section{REFERENCES}

Allen, F., Demirgüç-Kunt, A., Klapper, L., \& Peria, M. S. (2016). The Foundations of Financial Inclusion: Understanding Ownership and Use of Formal Accounts. Journal of Financial Intermediation, 27, 1-30.

Bank Indonesia. (2018). Statistik Sistem Keuangan Indonesia. Retrieved from Bank Indonesia: https://www.bi.go.id/id/statistik/sski/default.aspx

Beck, T., Demirgüç-Kunt, A., \& Honohan, P. (2009). Access to financial services : measurement, impact, and policies. The World Bank research observer, 24, 119145. 
Beck, T., Demirgüç-Kunt, A., \& Levine, R. (2007). Finance, Inequality, and the Poor. Journal of Economic Growth, 12, 27-49.

Brune, L., Giné, X., Goldberg, J., \& Yang, D. (2011). Commitments to Save: A Field Experiment in Rural Malawi. World Bank Policy Research Working Paper No. 5748.

Burgess, R., \& Pande, R. (2005). Do Rural Banks Matter? Evidence from the Indian Social Banking Experiment. American Economic Review, 95, 780-795.

Cámara, N., \& Tuesta, D. (2014). Measuring Financial Inclusion: A Multidimensional Index. BBVA Working Paper No. 14/26.

Greenwood, J., \& Jovanovic, B. (1990). Financial Development, Growth, and the Distribution of Income. Journal of Political Economy, 98, 1076-1107.

Honohan, P. (2008). Cross-Country Variation in Household Access to Financial Services. Journal of Banking and Finance, 32, 2493-2500.

Jeanneney, S. G., \& Kpodar, K. (2011). Financial Development and Poverty Reduction: Can There be a Benefit without a Cost? Journal of Development Studies, 47, 143-163.

Kim, D.W., Yu, J.S., \& Hassan, M. K. (2018). Financial Inclusion and Economic Growth in OIC Countries. Research in International Business and Finance, 43, 1-14.

Kuri, P. K., \& Laha, A. (2011). Financial Inclusion and Human Development in India: An Inter-State Analysis. Indian Journal of Human Development, 5, 61-77.

Leyshon, A., \& Thrift, N. (1995). Geographies of Financial Exclusion: Financial Abandonment in Britain and United States. Transactions of the Institute of British Geographers, 20, 312-241.

Narayan, P. K., \& Popp, S. (2010). A New Unit Root Test with Two Structural Breaks in Level and Slope at Unknown Time. Journal of Applied Statistics, 37, 1425-1438.

Narayan, P. K., \& Popp, S. (2013). Size and Power Properties of Structual Break Unit Root Tests. Applied Economics, 45, 721-728.

Neaime, S., \& Gaysset, I. (2018). Financial Inclusion and Stability in MENA: Evidence from poverty and Inequality. Financial Research Letters, 24, 230-237.

OECD. (2008). Handbook on constructing composite indicators: methodology and user guide. Retrieved from http://www.oecd.org/sdd/42495745.pdf

Otoritas Jasa Keuangan. (2017). Laporan Triwulanan: Triwulan IV-2017. Retrieved from Otoritas Jasa Keuangan: https://www.ojk.go.id/id/data-dan-statistik/ laporan-triwulanan/Pages/Laporan-Triwulan-IV---2017.aspx

Park, C.Y., \& Mercado Jr., R. V. (2015). Financial Incluion, Poverty, and Income Inequality in Developing Asia. ADB Economics Working Paper Series No. 426.

Park, C.Y., \& Mercado Jr., R. V. (2018). Financial Inclusion: New Measurement and Cross-Country Impact Assessment. ADB Economics Working Paper Series No. 539.

Saltelli, A. (2007). Composite indicators between analysis and advocacy. Social Indicators Research, 81, 65-77.

Sanjaya, I. M., \& Nursechafia. (2016). Inklusi Keuangan dan Pertumbuhan Inklusif: Analisis Antar Provinsi di Indonesia. Buletin Ekonomi Moneter dan Perbankan, $18,281-306$. 
Sarma, M. (2012). Index of Financial Inclusion - A measure of financial sector inclusiveness. Berlin Working Paper on Money, Finance, Trade and Development No. 7.

Sarma, M., \& Pais, J. (2011). Financial Inclusion and Development. Journal of International Development, 23, 613-628.

Sharma, D. (2016). Nexus between Financial Inclusion and Economic Growth: Eveidence from the emerging Indian Economy. Journal of Financial Economic Policy, 8, 13-36.

Sharma, S. S., \& Syarifuddin, F. (2019). Determinants of Indonesia's Income Velocity of Money. Bulletin of Monetary Economics and Banking, 21, 323-423.

Umar, A. I. (2017). Index of Syariah Financial Inclusion in Indonesia. Buletin Ekonomi Moneter dan Perbankan, 20, 99-126.

Ummah, B. B., \& Nuryantono, N. (2013). Analisis Keterkaiitan Inklusi Keuangan dengan Pembangunan di Asia. Bogor: Central Library of Bogor Agricultutal University.

Ummah, B. B., Nuryartono, N., \& Anggraeni, L. (2015). Analisis Inklusi Keuangan dan Pemerataan Pendapatan di Indonesia. Jurnal Ekonomi dan Kebijakan Pembangunan, 4, 1-27.

World Bank. (2017). The Global Findex Database 2017. Retrieved from World Bank: https://globalfindex.worldbank.org/ 
This page is intentionally left blank 